3. From: (originating Organization) NUMATEC Hanford Corporation Process Engineering Analysis

5. Proj./Prog./Dept./Div.:

PFP

8. Originator Remarks:

Transmittal of HNF-2590, Rev. 0, "Thermal Response of Can handling Unit (CHU) to a Postulated Plutonium Hydride Burn"
Engr.:

F. J. Heard
4. Related EDT No.:

$\mathrm{N} / \mathrm{A}$

7. Purchase Order No.:

$\mathrm{N} / \mathrm{A}$

9. Equip./Component No.:

$N / A$

10. System/Bldg./Facil lity: $N / A$

11. Receiver Remarks: 11A. Design Baseline Document? [] Yes [X] No
12. Major Assm. Dug. No.:

N/A

13. Permit/Permit Application No.: $N / A$

14. Required Response Date: May 6, 1998

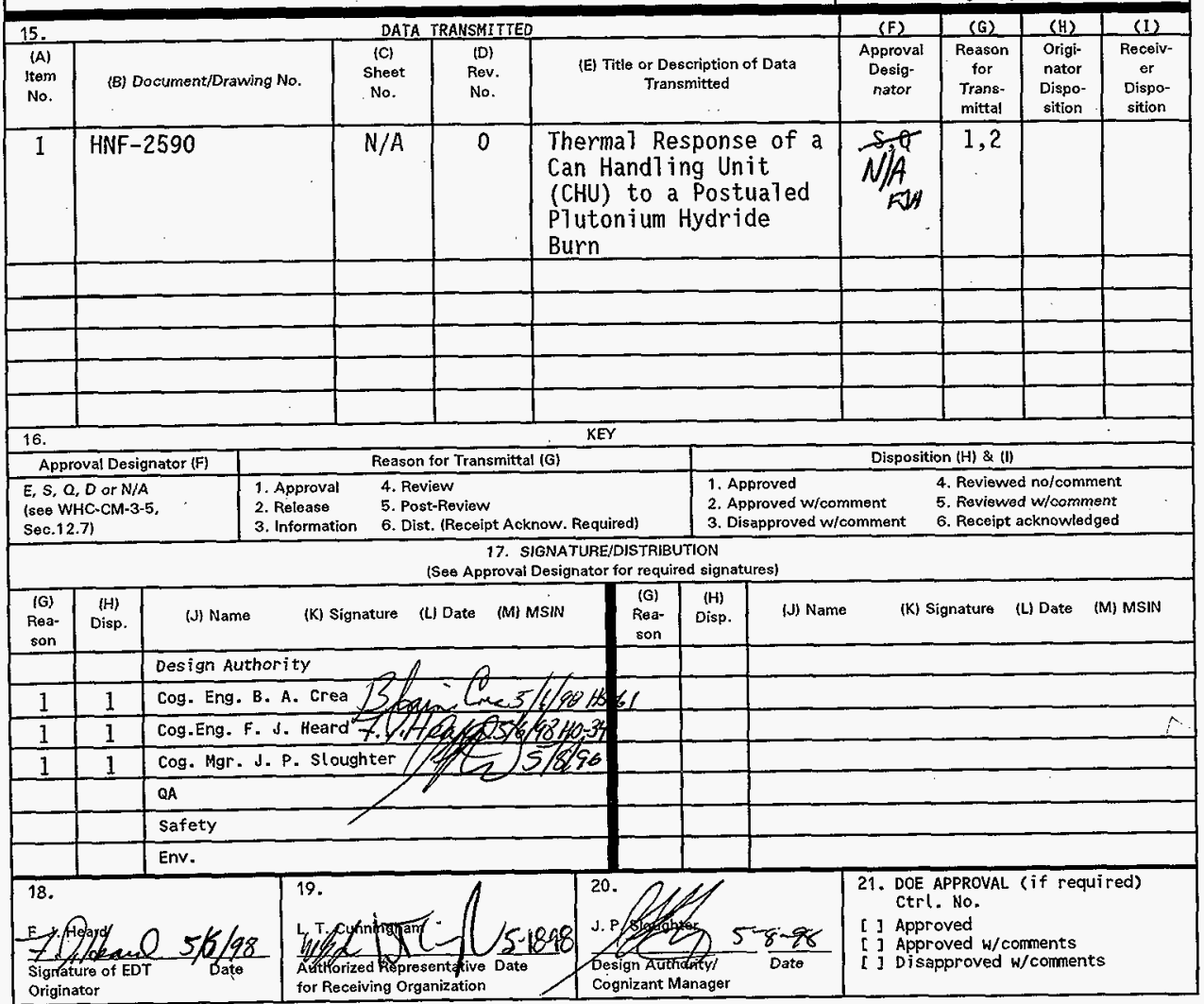




\title{
Thermal Response of a Can Handling Unit (CHU) to a Postulated Plutonium Hydride Burn
}

\author{
B. A. Crea and F. J. Heard
}

NUMATEC Hanford Corporation, Richland, WA 99352

U.S. Department of Energy Contract DE-AC06-96RL13200

$\begin{array}{llll}\text { EDT/ECN: } & 608767 & \text { UC: } 721 \\ \text { Org Code: } & \text { UC530000 } & \text { Charge Code: } & \text { E55839 } \\ \text { B\&R Code: } & \text { EW7040000 } & \text { Total Pages: } & 30\end{array}$

Key Words: Plutonium Hydride, Transient Temperatures, Thermal Response, Can Handling Unit, Chemical Reactions, Storage Can

Abstract: A series of analyses were performed to support the design of the Can Handling Unit (CHU). The subject analyses focused on determining the time to repressurize a subatmospheric storage can containing plutonium metal versus the initial hole size and the transient thermal response to a postulated chemical reaction of 150 grams of plutonium hydride. Limiting the amount of gaseous reactants either by inerting the CHU or using a very small hole size for the initial opening appears to be a viable method of controlling the rate of the exothermic chemical reactions and system temperatures.

TRADEMARK DISCLAIMER. Reference herein to any specific commercial product, process, or service by trade name, trademark, manufacturer, or otherwise, does not necessarily constitute or imply its endorsement, recommendation, or favoring by the United States Government or any agency thereof or its contractors or subcontractors.

Printed in the United States of America. To abtain copies of this document, contact: WHC/BCS Document Control Services, P.O. Box 1970, Mailstop H6-08, Richland WA 99352, Phone (509) 372-2420; Fax (509) 376-4989.

$\frac{\text { Lamia Aardel } 5-21 \cdot 98}{\text { Date }}$

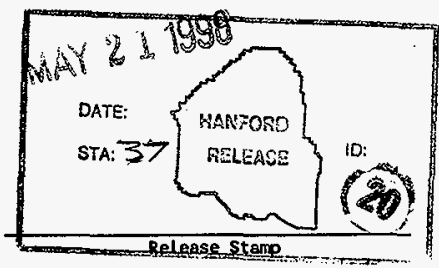


HNF-2590, Rev. 0

Thermal Response of a Can Handling Unit (CHU)

to a Postulated Plutonium Hydride Burn

Prepared by:

B. A. Crea

F. J. Heard

Numatec Hanford Corporation

Apri1 1998 
HNF-2590, Rev. 0

TABLE OF CONTENTS

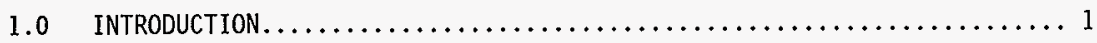

1.1 Purpose and objective...............................

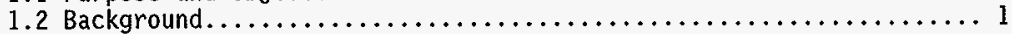

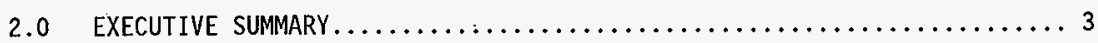

3.0 ANALYSIS METHODOLOGY AND ASSUMPTIONS.................... 4

3.1. Problem Definition and Required Analyses.................. 4

3.1.1 Description of Can Handling Unit (CHU) ............... 5

3.1.2 Description of the G1ovebox Thermal Mode1............ 5

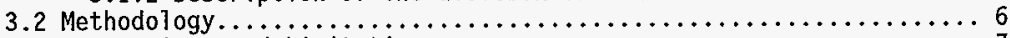

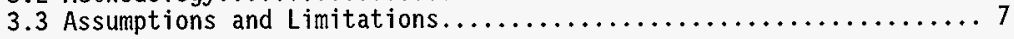

$4.0 \quad$ RESULTS.......................................... 10

4.1 Time To Fill Versus Hole Size......................... 10

4.2 Diffusion limited Hydride Reaction....................... 10

4.2.1 Temperatures.................................. 10

4.2.2 Energy Transport.............................. 10

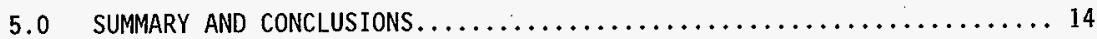

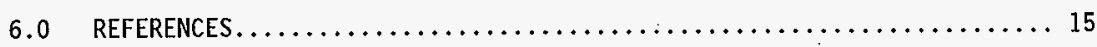

APPENDICES: A - Energy Production Rate for Air Source Based on Convective and Diffusive Mass Transport

B - User FORTRAN Subroutine for Rate of Chemical Energy Production Versus Time

C - Time to Fill CHU Versus Hole Size 
HNF-2590, Rev. 0

\subsection{INTRODUCTION}

\subsection{PURPOSE AND OBJECTIVE}

The purpose of this report is to document the results of a series of analyses that were performed to support the design of a proposed Can Hand 7 ing Unit (CHU). The CHU is being developed to provide personnel protection for safely opening storage cans containing plutonium metal. The CHU is described in Section 3.2.1.

The objective is to control the rate of air ingress into the storage can such that the reaction of plutonium hydride $\left(\mathrm{PuH}_{3}\right)$ with air will not result in a rate of energy release sufficient to overpressurize and possibly expel the remaining hydride into the glovebox atmosphere.

The subject analyses focused on determining the time to repressurize a subatmospheric storage can versus the initial hole size (i.e. puncture). In addition, the transient temperature response of a $2.2 \mathrm{~kg}$ mass of plutonium to a postulated burn of 150 grams of plutonium hydride $\left(\mathrm{PuH}_{3}\right)$ was analyzed. As documented in Redekopp 1997, a glovebox overpressure on the order of several psi would result if the maximum postulated amount (150 grams) of $\mathrm{PuH}_{3}$ and the glovebox atmosphere (i.e., air) were mixed together in a very smal1 time frame (the existing gloveboxes are large enough to contain enough air to allow the hydride reaction to be carried to completion) and the heat of reaction was adiabatically deposited within a glovebox's atmosphere.

\subsection{BACKGROUND}

Plutonium is chemically a very reactive metal. Various chemical reactions with plutonium metal can produce corrosion products such as, plutonium oxides, hydrides, and nitrides depending on the presence and concentrations of oxygen, nitrogen, hydrogen. The hydrides form from hydrogen that is postulated to be released from the irradiation induced degradation of the PVC or PE bags used during the handling process and sealed within the storage container.

Some of these corrosion products, especially plutonium hydride are pyrophoric and will react very quickly when exposed to atmospheric concentrations of oxygen (approximately $21 \%$ by volume). The rate of the chemical reactions depends on the local temperature and the local concentration of the various reacting species, which in turn are controlled by the mixing action of the flow fields. The effects of chemical reactions on system thermal and pressure response are dependent on the interrelated rates of mass, momentum, and energy transport.

While opening a plutonium metal storage container, known to be paneled (buckled inward), a sparking, glowing reaction was observed and filmed at the Plutonium Finishing Plant (PFP). The rapid reaction observed was determined 


$$
\text { HNF-2590, Rev. } 0
$$

to be plutonium hydride powder reacting with oxygen in air introduced as the can was punctured. An occurrence report was generated and a positive Unresolved Safety Question Determination (USQD) resulted from this event and is documented by Redekopp 1997. The USQD indicated that the potential existed for a glovebox overpressure on the order of several psi if the maximum postulated amount (150 grams) of $\mathrm{PuH}_{3}$ was dispersed into and reacts with the glovebox's atmosphere (i.e., air) and the heat of reaction was adiabatically deposited within a glovebox's atmosphere. This overpressure was not bounded by the existing authorization basis.

A positive USQD requires that a Justification for Continued Operation (JCO) with adequate compensatory measures be submitted to the Department of Energy (DOE) before operations can be resumed. The concept of the can handling unit (CHU) resulted as one of the proposed compensatory measures and is supported by the analyses described within this report. 
HNF-2590, Rev. 0

\subsection{EXECUTIVE SUMMARY}

Limiting the initial amount of and/or rate at which the reacting species are supplied, or preventing the $\mathrm{PuH}_{3}$ from forming a cloud, are the only practical mechanisms that can be used to affect the rate of energy production based on current uncertainties regarding the corrosion products that might be present in a storage can. Therefore, the proposed Can Handling Unit (CHU), which isolates the storage can within an inerted Argon system during the initial opening and gradually dilutes the initial Argon atmosphere with standard air, hereby, limiting the amount of gaseous reactants, appears to be a viable method of controlling the rate of the chemical reaction (i.e., energy production) and, hence, system temperature and pressure increase.

If the storage can is opened in air, simple thermal models (Redekopp 1997) have shown that the resulting energy release and transient pressure rise from the chemical reactions with plutonium hydride and the initial inrush of air are sufficient to produce a short duration flow of hot gas out of the can. The simple thermal analyses discussed within this report do not address this scenario. More detailed models and analyses are required to investigate the thermal and pressure transients given the initial opening of storage can in air. It is postulated that the velocity of the outflow falls within the envelope of velocities and ratios of flow rate-to-mass being transported that are considered necessary to suspend and convey some $\mathrm{PuH}_{3}$ powder out of the can. There are several qualitative factors (such as transient versus steady state, the initial pressures, free volume, geometry of the powder bed, rates of various chemical reactions, etc.,.) that will influence the actual

entrainment and potential expulsion. 
HNF-2590, Rev. 0

\subsection{ANALYSIS METHODOLOGY AND ASSUMPTIONS}

As documented in Redekopp 1997, a glovebox overpressure on the order of several psi would result if the maximum postulated amount (150 grams) of $\mathrm{PuH}_{3}$ and the glovebox atmosphere (i.e., air) were mixed together in a very smal1 time frame and the heat of reaction was adiabatically deposited within a glovebox's atmosphere.

The assumption that all of the energy from a chemical reaction is deposited adiabatically with in the glovebox atmosphere is conservative. If the hydride is reacted within the storage can and because of the relatively high thermal conductivity of Pu metal, it is expected that much of the energy from a hydride burn would be deposited within the Pu metal mass and will be gradually released to the surrounding system.

\subsection{PROBLEM DEFINITION AND REQUIRED ANALYSES}

Plutonium is chemically a very reactive metal. Earlier this year while opening a plutonium metal storage container, known to be paneled (buckled inward), a sparking, glowing reaction was observed and filmed at the Plutonium Finishing $P$ lant (PFP). A solution was determined to 1 ay with reducing the rate of energy production from chemical reactions during the initial opening of the storage can.

The CHU, as designed, will control the rate of air ingress to the storage can, such that the reaction of plutonium hydride $\left(\mathrm{PuH}_{3}\right)$ with air will not result in a rate of energy release sufficient to overpressurize and possibly expel the remaining hydride into the glovebox atmosphere. The CHU employs two methods for controlling ajr ingress. These are:

1.) Use of inerted cover gas to control the concentration of air.

2.) Decrease the suppiy rate for air by use of a smail hole size for the initial opening of the storage containers

Both of these methods are expected to be very effective in controlling the rate at which air can be supplied to react with the postulated 150 grams of $\mathrm{PuH}_{3}$ within the storage can. Hence, the rate of energy production from chemical reactions will be reduced and overpressurization of the storage can be avoided.

A simple axi-symmetric thermal model was constructed of a glovebox containing a storage can with a $2.2 \mathrm{~kg}$ mass of Pu metal within a CHU. The heat source was assumed to be from nuclear decay and chemical reactions. The nuclear decay heat was assumed to remain constant at 15 watts for the $2.2 \mathrm{Kg}$ mass. The rate of chemical energy generation will vary depending on the rate at which air is supplied to the storage can. Appendix A documents the calculation that was performed to determine the rate of energy production for a diffusion limited supply rate for air and reactant mass limitation of 150 
HNF-2590, Rev. 0

grams of $\mathrm{PuH}_{3}$. A user FORTRAN subroutine (Appendix B) was written to calculate the energy associated with a chemical reactions as a function of time for a postulated burn of 150 grams of $\mathrm{PuH}_{3}$.

\subsubsection{Description of Can Handling Unit (CHU)}

A conceptual design of the can handling unit (CHU) is presented by Figure 1. The CHU will be used for the initial opening storage cans that contain plutonium metal. The CHU dimensions will be approximately $12^{\prime \prime} \times 16^{\prime \prime} \times$ $6^{\prime \prime}$ and will be constructed from 16 gage stainless steet. The CHU will be water tight. The box will have a Lexan window on the front. The unit will have an oxygen monitor, a pressure/vacuum gauge, and a thermocouple (to measure can temperature). Both argon and normal glovebox air will be piped to the unit. The unit will have a small pump capable of $0.2 \mathrm{scfm}$ maximum flow air into the CHU. The maximum allowable mass of plutonium $(2.2 \mathrm{Kg})$ metal occupies about $50 \%$ of the free volume in the storage can.

A hand puncturing device (with 3 points $1 / 4$ " diameter) will be used to puncture each can. The CHU will be capable of accommodating and puncturing different can sizes that have been used to store plutonium metal. This is especially important for those storage containers with multiple layers of nested cans. It is anticipated that each can layer will be sequentially removed using a can opener prior to puncturing and removing the upper lid from the innermost can.

\subsubsection{Description of the Glovebox Thermal Mode1}

A very simple axi-symmetric (cylindrical coordinates) finite-difference thermal model of a glovebox with a storage can was constructed using the HEATING 7.2 computer code (Childs 1993). The HEATING 7.2 code solves steadystate and transient heat conduction problems only for one-, two-, or threedimensional Cartesian, cylindrical, and spherical coordinates. No flow fields or species concentrations were solved for. However, the effects of both thermal radiation and convective heat transfer from both forced and naturat circulation flow fields can be incorporated into the heat transfer coefficients that are applied to the various surfaces. The effects of mass transport have been incorporated into the production rate of chemical energy.

The glovebox was assumed to be 8 feet wide, 4 feet high, and 4 feet deep for an internal volume of 128 cubic feet. An equivalent radius of 3.1915 feet was derived for a given height of 4 feet. The storage can was assumed to be centered and resting on the lower internal surface of the glovebox. Contact resistance between the storage can and the glovebox was not modeled.

The plutonium storage can was assumed to be similar to a small "soup" can with an outer diameter of 2.625 inches and a overa11 height of 2.875 inches. Wall thickness was assumed to be 0.009 inches. The upper and lower surfaces were sealed using an overwrapped interlocking 1 ip seal that results in a small (0.110 inches) raised rim. It is important to note that this rim 
HNF-2590, Rev. 0

results in a very small bottom gap between the storage can lower outer surface and the glovebox. Simulation results (Heard 1997) of recent storage can thermal tests showed the importance of modeling the lower gap.

The storage can was assumed to contain a $2.2 \mathrm{Kg}$ piece of plutonium metal cast in the form of a right circular cylinder. The density of the metal was assumed to be $18.9 \mathrm{~g} / \mathrm{cm}^{3}$, which results in a Pu metal volume of approximately $116.4 \mathrm{~cm}^{3}$. A radial gap of approximately 0.3 inches between the outer surface of the Pu metal and inner surface of the storage can was derived using an assumed Pu diameter of 2 inches. An axial gap of approximately, 0.376 inches can be derived from the previous information.

The energy transport within the storage container was assumed to occur due to conduction and surface-to-surface thermal radiation across the various sized air gaps. The storage container internal gaps were assumed to be small enough that the air was assumed to be stagnate (i.e., no convective heat transfer).

Energy transport external to the storage can and internal to the glovebox incorporated convective heat transfer terms for natural circulation based systems, as we 11 as conduction and thermal radiation. The coefficients for the natural circulation heat transfer correlations were obtained from Holman (Table 7-2, 1990).

Heat transfer from the outermost surfaces of the glovebox was assumed to occur via natural convection and thermal radiation to a ambient temperature of $77 \mathrm{~F}(25 \mathrm{C}, 298.16 \mathrm{~K})$.

The assumed emissivities were as follows: 0.25 for bright shiny stainless steel or white oxidized aluminum, 0.80 for glass, 0.05 for tinplated mild carbon steel (i.e., the storage can). The low value of emissivity for provides a limiting case, since oxidized tin-plated mild carbon steel can be expected to have emissivities and resulting radiative heat transfer well in excess of this value.

\subsection{METHODOLOGY}

The rate of energy production from reactions with plutonium hydride $\left(\mathrm{PuH}_{3}\right)$ powder can be controlled as follows;

1. The amount and form of the plutonium hydride powder can be such that only a small fraction of the maximum postulated 150 grams may be present or in a form available to react at any one time.

2. The initial amount and rate at which the reacting species (i.e., atmospheric gases) is supplied to the plutonium hydride powder can be 1 imited. 


$$
\text { HNF-2590, Rev, } 0
$$

3. The initial temperature is maintained low enough to prevent the reaction from occurring at a rate greater than the ability to reject the rate of energy production.

Limiting the amount and form of the plutonium hydride powder cannot be applied to this problem; since, experience has shown that Plutonium Hydride $\left(\mathrm{PuH}_{3}\right)$ will be in the form of a fine powder and the initial amount of p.lutonium hydride within a closed container cannot be readily determined. Therefore, a maximum amount of 150 grams of $\mathrm{PuH}_{3}$ was assumed to exist within the storage cans based on the presence of various sources of hydrogen (PVC and PE bags and some initial trace amount of water).

Two additional analyses were performed to investigate the effects associated with item number 2 from above. The first analysis used the glovebox thermal model, as described in Section 3.1.2, to determine the temperatures obtained from a postulated burn of 150 grams of $\mathrm{PuH}_{3}$ within a storage can. The second analysis, used a MATHCAD model (See Appendix C) to determined the time versus hole size required to return a subatmospheric can to fu11 atmospheric pressure.

The first analysis determined the time required to react 150 grams of $\mathrm{PuH}_{3}$ and maximum temperatures that could occur within a storage can with a convection and diffusion limited source of air. This analysis assumed that all of the $\mathrm{PuH}_{3}$ remained within the storage can and was not expelled into the glovebox's atmosphere as previous analyses had assumed. This analysis simulated the initial opening of the storage can within an inerted $\mathrm{CHU}$, the slow dilution of the CHU's initial atmosphere with air $(0.2 \mathrm{CFM})$, and diffusion of air into the storage can. Three $1 / 4$ inch holes were assumed to be punctured in an inerted atmosphere to initialiy vent or repressurize the can.

The second analysis determined the time versus hole size required to return a subatmospheric can to full atmospheric pressure. Smaller hole size limits that rate at which air can be transferred into the storage can and, therefore, limits the rate of energy production due to chemical reactions.

The second analysis is based on the assumption that the first $53 \%$ of the air ingress is at sonic velocities and the balance occurs based on the Bernoulli Equation for a given pressure differential.

\subsection{ASSUMPTIONS AND LIMITATIONS}

The following items summarize the major assumptions, limitations, and technical bases for the subject analyses;

1.) A coupled thermal-hydraulic analysis (i.e., heat, mass, and momentum) simulating the initial opening of a storage can within an inerted CHU was not performed. The simple thermal analysis that was performed was judged to be conservative for analyzing the initial 
HNF-2590, Rev. 0

opening of a storage can within an inerted CHU. This is possible as long as the mitigating affects of increasing pressure within the storage can as a result of the chemical reactions are not accounted for.

(Increased internal pressure will reduce the pressure differential and, hence, the rates of air inflow and chemical reactions within the storage can will be reduced.)

2.) If the storage can is opened in air, simple thermal models (Redekopp 1997) have shown that the resulting energy release and transient pressure rise from the chemical reactions with plutonium hydride and the initial inrush of air are sufficient to produce a short duration flow of hot gas out of the can. The simple thermal analyses discussed within this report are not adequate to address this scenario. More detailed models and analyses are required to investigate the thermal and pressure transients given the initial opening of storage can in air.

3.) The storage can was assumed to be fabricated from bright tin-plated carbon steel with a normal hemispherical surface emissivity of 0.05 .

4.) The storage can was assumed to contain $2.2 \mathrm{Kg}$ of Pu metal and 150 grams of $\mathrm{PuH}_{3}$. The hydride layer was assumed to be uniformly distributed across the outer and upper surface to a depth of 10 mils.

5.) A maximum expected nuclear decay heat of 15 watts $(\mathrm{J} / \mathrm{s})$ was assumed to be uniformly distributed throughout both the Pu metal and hydride.

6.) A user FORTRAN subroutine was written to incorporate a time dependent chemical reaction energy source (see Appendices $A$ and $B$ ) based on convective transport and diffusion of oxygen to the reaction surface. 
HNF-2590, Rev. 0

Figure 3-1. Conceptualized Design of a Can Hand7ing Unit.

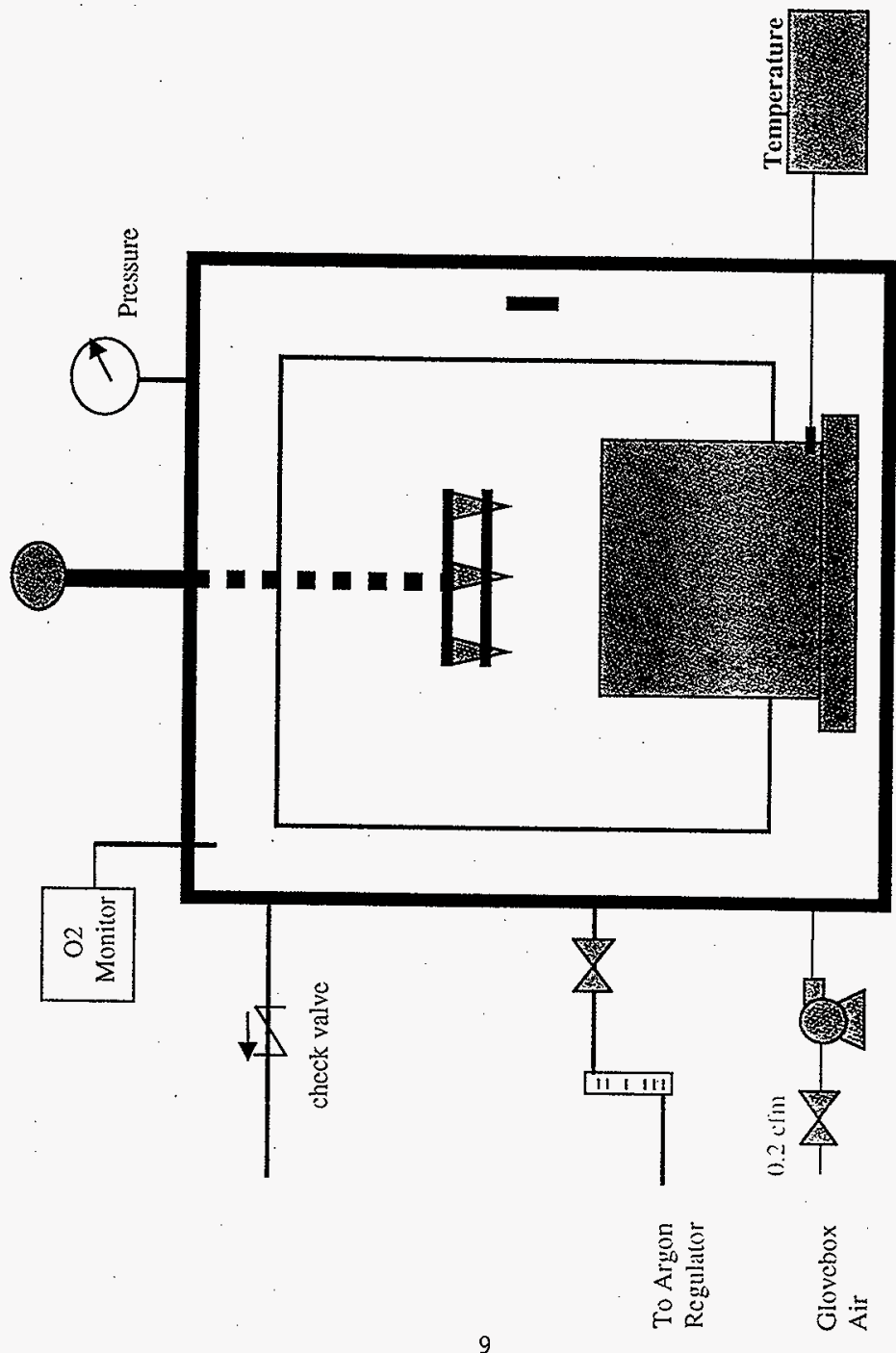


HNF-2590, Rev. 0

\subsection{RESULTS}

The following results were obtained from the simple models constructed to simulate the process of the initial opening of a sealed storage can within an inerted CHU.

\subsection{TIME TO FILL VERSUS HOLE SIZE}

Figure 4-1 presents the time at choked flow and the time to reach $95 \%$ of atmospheric pressure for a pressure differential of $14.7 \mathrm{psi}$. For a hole size of $5 \mathrm{~mm}$ ( 0.197 inches) the time to reach 95\% of atmospheric pressure is on the order of 0.02 seconds. For a much smaller hole size of $0.25 \mathrm{~mm}(0.0098$ inches, i.e., $10 \mathrm{mils}$ ) the time to reach $95 \%$ of atmospheric pressure is on the order of 18 seconds. Therefore, the smaller the hole size is during the initial opening, the longer it takes to provide reactants for the hydride reaction. Therefore, since the rate of reaction is dependent on the concentration of air, the smaller the initial hole size the slower the reaction rate. By limiting the amount of reactants available for the hydride reaction, the rate of energy production can be controlled and the transient temperature rise can be minimized.

\subsection{DIFFUSION LIMITED HYDRIDE REACTION}

\subsubsection{Transient Temperatures}

Figure 4-2 presents the peak transient temperature versus time for a $\mathrm{CHU}$ positioned within a glovebox given an initial opening of three holes each 0.25 inches in diameter. The peak transient temperatures was predicted to be approximately $710^{\circ} \mathrm{K}\left(819^{\circ} \mathrm{F}\right)$. This is considerable less than previous estimates.

The rate at which air is transported into the storage can and, hence, rate of energy production, is based on diffusion and convective mechanisms; where the nominal diffusion length is approximatel.y $1 \mathrm{~cm}$. By Timiting the rate at which mass is added to the system, the rate of energy production is reduced and the peak transient temperature is reduced. Appendix $A$ indicates that approximately 1260 seconds are required to completely react 150 grams of $\mathrm{PuH}_{3}$ given the nominal diffusion length of $1 \mathrm{~cm}$.

After one-and-a-haif hours of simulated cooling, the peak transient temperature has decreased to approximately $426{ }^{\circ} \mathrm{K}\left(307{ }^{\circ} \mathrm{F}\right)$, which can be compared to the initial peak temperature of $392^{\circ} \mathrm{K}\left(246{ }^{\circ} \mathrm{F}\right)$.

\subsubsection{Energy Transport}

An energy balance was performed at each time step during the above transient analysis. A review of the results indicate that approximately $89 \%$ of the total energy that is produced by nuclear decay heat and the hydride surface reaction is deposited within the plutonium button and gradually released over time. This is $p l$ ausible given the high thermal conductivity of 


$$
\text { HNF-2590, Rev. } 0
$$

the plutonium metal. The plutonium button acts like a energy sink and wicks the energy produced by the plutonium hydride reaction away from the reaction site.

Approximately $70 \%$ of the energy deposited within the plutonium button is removed via conduction through the bottom of the storage can and eventually by convective and radiative means from the lower outside surface of the glovebox. Approximately $25 \%$ is removed via the sides of the plutonium button and the remainder of $5 \%$ is removed from the upper surface. 
HNF-2590, Rev. 0

Figure 4-1. Time to Fill a Can Handling Unit to Atmospheric Pressure Versus Hole Size.

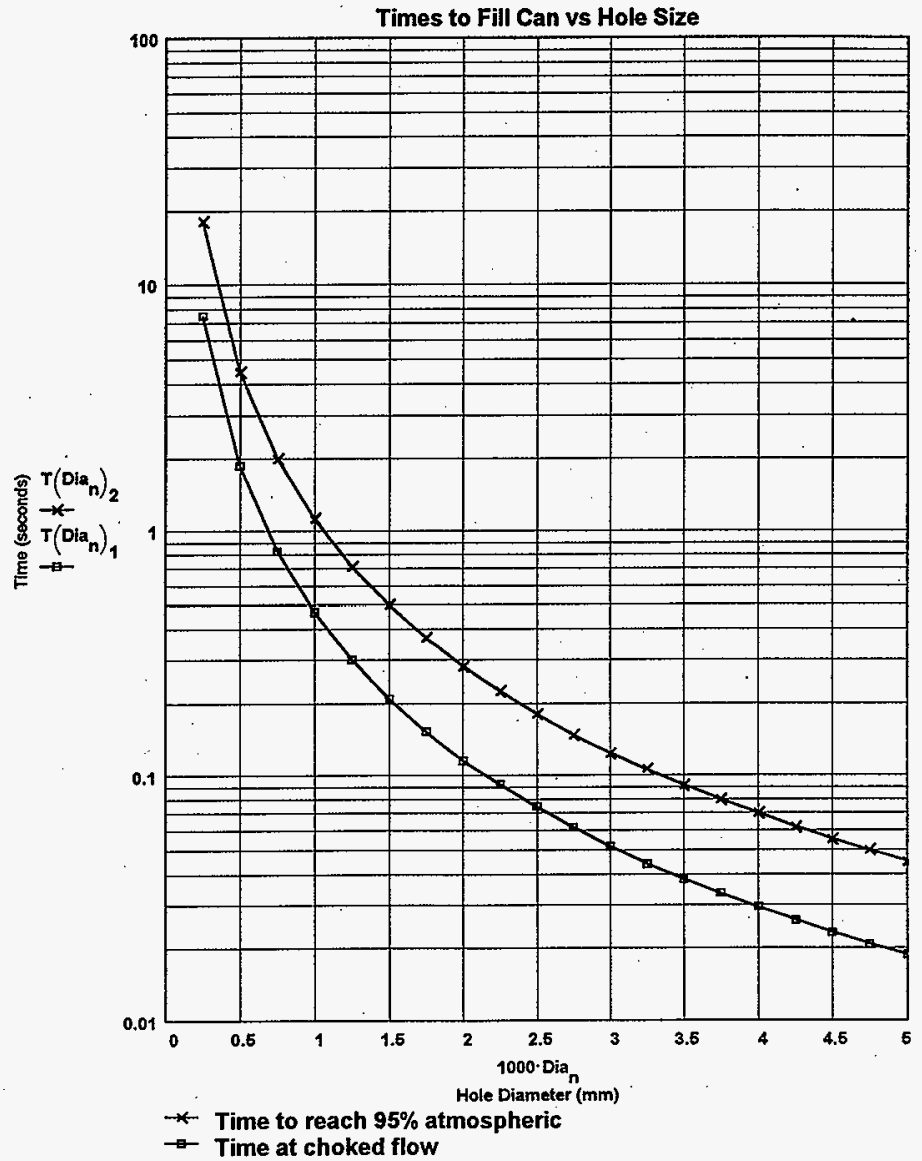


HNF-2590, Rev. 0

Figure 4-2. Peak Plutonium Temperature Versus Time for a Postulated Burn of 150 Grams of Plutonium Hydride In Air.

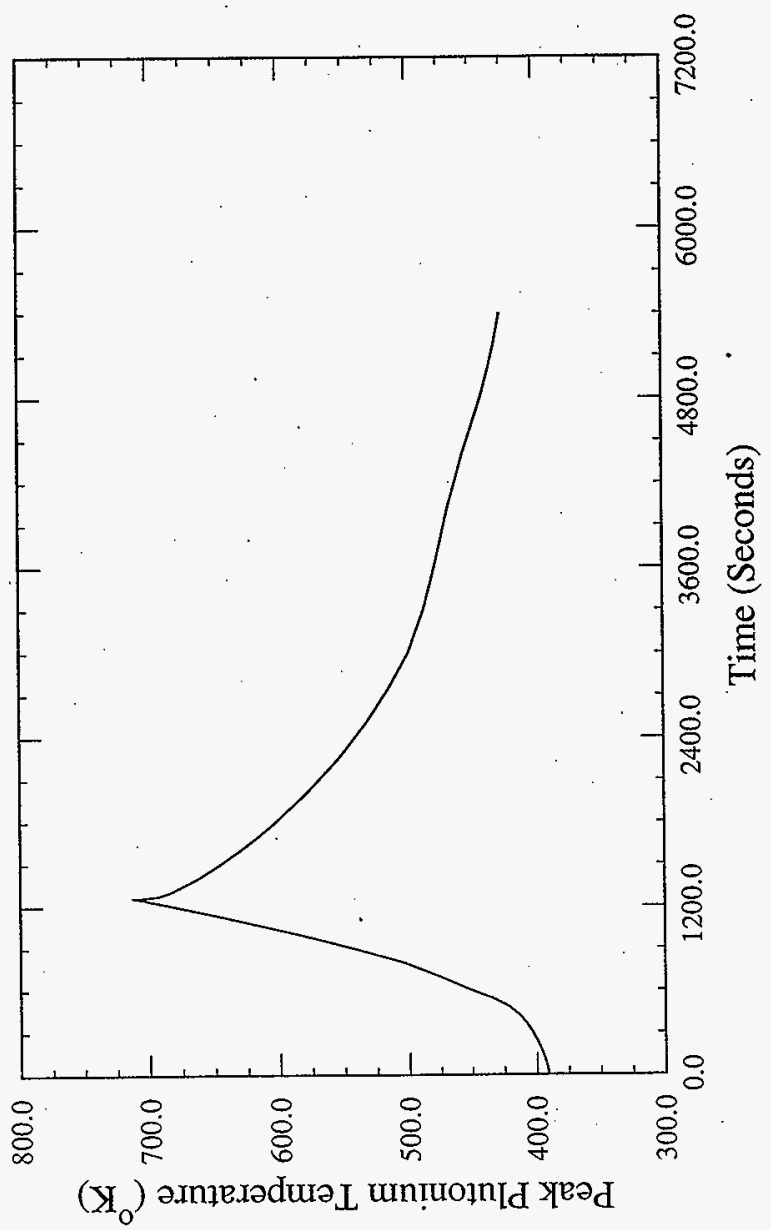


HNF-2590, Rev. 0

\subsection{SUMMARY AND CONCLUSIONS}

Analysis has shown that if the plutonium storage can is allowed to equalize pressure in an inert atmosphere so that the initial inrush of reactive gases is avoided, the reaction rate can be controlled by slowly diluting the inerted atmosphere with air. The rate of energy production will be slow enough using this method that enough energy can be deposited within the plutonium metal button within the can and slowly transferred to the surrounding ambient environment such that an glovebox overpressure event wi11 not occur. The results are considered conservative given that the model did not account for the mitigating affects of atmospheric heating which will limit the amount of air entering the storage can.

If the storage can is opened in air, simple thermal models have previously (Redekopp 1997) shown that the resulting energy release and transient pressure rise from the chemical reactions with plutonium hydride and the initial inrush of air are sufficient to produce a short duration flow of hot gas out of the can. The simple thermal models and analyses discussed within this report are not adequate to address this scenario. More detailed models and additional analyses are required to investigate the thermal and pressure transients resulting from an initial opening of a storage can in air. It is postulated that the velocity of the outflow falls within the envelope of velocities and ratios of flow rate-to-mass being transported that are. considered necessary to suspend and convey some $\mathrm{PuH}_{3}$ powder out of the can. There are several qualitative factors (such as transient versus steady state, the initial pressures, free volume, geometry of the powder bed, rates of various chemical reactions, etc.,) that will influence the actual entrainment and potential expulsion. 
HNF-2590, Rev. 0

\subsection{REFERENCES}

Redekopp, R. D. to L. J. 01quin, "Potential Unreviewed Safety Question PFP-9705: Plutonium Metal Reaction Upon Opening Item With Paneled Inner Container," Babcock and Wilcox Hanford Company, letter. BWHC-9755047, Revision 1, dated October 7, 1997.

Childs, K. W., "HEATING 7.2 Users' Manual," ORNL/TM-12262, Oak Ridge National Laboratory, Oak Ridge, Tennessee, dated February 1993.

Heard, F. J. to G. A. Johnston, et el., "Results of the Thermal-Hydraulic Assessment for the Hanford Convenience Can Storage Containers and Storage Racks," Numatec Hanford Company Internal memo 8C453-97-FJH-001, dated June 1997.

Holman, J. P., 1990, "Heat Transfer," Seventh Edition, McGraw-Hi11, Inc., New York, New York. 


\begin{abstract}
HNF-2590, Rev. 0
APPENDIX A

Energy Production Rate for Air Source Based on Convective and Diffusive Mass Transport
\end{abstract}


HNF-2590, Rev. 0

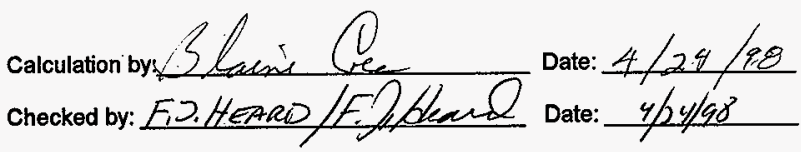

Page 1 of 5 pages

File for calculation of the effect of reacting up to $150 \mathrm{~g}$ of plutonium hydride in a can. This calculation assumes that at the start of the reaction the can has $3-1 / 4$ in holes punched in the top and is in a device called the Can Handing Unit (CHU), which has been inerted with argon while the holes are punched in the lid. Subsequent to punching the holes in the can the CHU (which had been inerted with argon) is supplied with air at a rate of $.2 \mathrm{scfm}$. As the air concentration builds up in the CHU the assumption is made that it will begin by diffusing into the holes in the can and reacting with the hydride. This calculation shows that as the contents of the can heat up due to the reaction of the hydride, that bouyancy based driving forces take over and drive the reaction to completion in a controlled, but expedient manner. The reaction energy calculations arebased on data provided by Thurman Cooper

Firs define some constants and parameters of the problem.

\section{Arflow :=.2 CFM Proposed flow rate of Air into the CHU to provide reactant}

MWhyd := $\frac{241}{10^{3}} \quad$ grams/mmole $\quad$ Molecular wt of Plutonium Hydride

Compute the heats of reaction due to the reaction of oxygen and nitrogen with the plutonium hydride powder. The Reactions are:

$\mathrm{PuH}_{2}+3 / 2 \mathrm{O}_{2} \rightarrow \mathrm{PuO}_{2}+\mathrm{H}_{2} \mathrm{O}$ and $2 \mathrm{PuH}_{2}+\mathrm{N}_{2} \rightarrow 2 \mathrm{PuN}+2 \mathrm{H}_{2}$

HRO2 $:=\frac{(2 \cdot-241.826+2 \cdot-1084.899)-2 \cdot-127.194}{3.0}$ Joules $/ \mathbf{m m o l e}^{-O_{2}}$

HRO2 $=-799.68733$

HRN2 := (2-290.78 - 2--127.194) Joules/mmole- $\mathrm{N}_{2}$

HRN2 $=-327.172$

Diffusion coefficient for air through Argon into the can. $\quad$ Dab := .18.0001 $M^{2} / \mathrm{sec}$

Note: molecular diffusion will be overridden by convective processes, once significant temperature differences are established in the $\mathrm{CHU}$ (probably about $20^{\circ} \mathrm{C}$ and for sure at differences in excess of $50^{\circ} \mathrm{C}$ )

pair := .0764.16.01 $\mathrm{Kg} / \mathrm{M} 3 \quad$ Standard density of air in SI units $\quad$ pair $=\mathbf{1 . 2 2 3 1 6}$

Cair : $=\frac{\text { pair }}{28.95} \cdot 10^{6} \quad$ mmoles $/ M^{3} \quad$ Molar density of air in milli-moles/cubic meter

$$
\text { Cair }=4.22509 \cdot 10^{4}
$$

Define the effective diffusion length for diffusion of air into the Difl := .01 M can as $1 \mathrm{~cm}$

Define the area of the opening for diffusion or bouancy driven flow of air into the can and reaction products out of the can.

Difa $:=3 \cdot\left(\frac{\pi}{4}\right) \cdot(.25 \cdot .0254)^{2} \quad$ Difa $=9.50077 \cdot 10^{-5}$ 


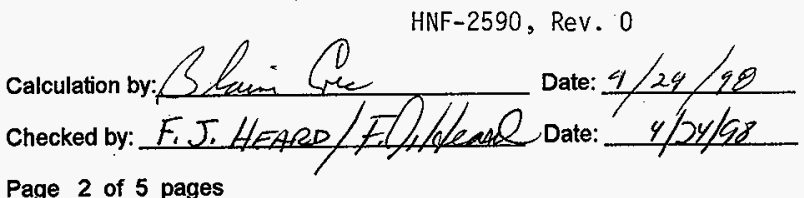

Define a program to compute the end point temperature reached by the plutonium button in the can due to the reaction of the plutonium hydride in the can with both the oxygen and the nitrogen in the air. The assumption is made that the can handling unit is initially filled with Argon and then air is bled in at the rate of .2 CFM to react with the hydride. This program should also return the time required to react all the hydride powder the an indication of whether the flow is turbulent or laminar (reynolds number) and the total air required as a function of the inventory of hydride powder in the CHU "M in grams"

This program makes use of approximation, the derivation which is in "Boundary Layer Theory" by Schlichting. The approximation is that for flow conditions which are represented by very small velocities and considerable temperature differences which is the case for this condition that $\mathrm{Gr}$ (Grashof \#) = Re? (Reynolds \# squared). This leads to the expression for the air mass fiux as a sum of both the diffusion terms as well as the bulk velocity. This is taken from the formulation presented in "Transport Phenomenon" Bird Stewart and Lightfoot. Provisions have also been added to make the characteristic length and differential time step as an argument. This allows the diffusion only case to be run for comparison purposes, as well as showing that for reasonable values of characteristic length the results are quite similar.

Equating the grashof number to the reynolds number squared results in this eqn $\rho^{2} \mathrm{~g} \beta\left(\mathrm{T}-\mathrm{T}_{\mathrm{o}}\right) \mathrm{L}^{3 / \mu^{2}}=(\mathrm{VL} \rho / \mu)^{2} \quad$ Note that $\beta=1 / \mathrm{To}_{0}$.

After canceling out the density and viscosity terms the remaining equation is a relationship for a charcteristic velocity as a function of temperature differences, a characteristic length, and the acceleration of gravity.

This term is used as the velocity term for convective movement of air into the can in the CHU. It is added directly to the diffusion velocity.

$$
V=s q r t\left(g L\left(T-T_{0}\right) / T_{0}\right)
$$

Additional parameters that are required to characterize the flow in terms of buoyancy forces are the acceleration of gravity and a characteristic length. The characteristic length will be chosen as $1 \mathrm{~mm}$.

$$
\begin{array}{lll}
\text { ga : }=9.8 \quad \mathrm{~m} / \mathrm{sec} 2 & \text { gravitational acceleration } \\
\text { Lchar to } .001 \mathrm{~m} & \text { characteristic length for free convection process }
\end{array}
$$

Input arguments to the program are the mass of hydride to be reacted, characteristic length for the convective process, and time step for the iterative loop respectively.

The output vector elements are the time required to consume the hydride, the adiabatic endpoint temperature of the button, The amount of air consumed in milli-moles, the number of iterations and the Reynolds number from top to bottom. 
HNF-2590, Rev. 0

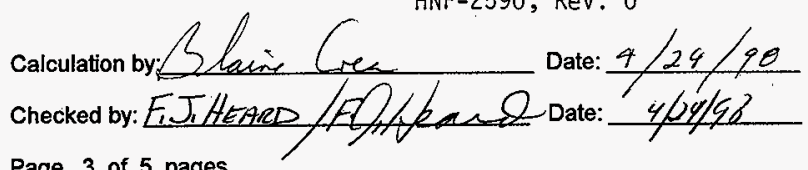

Page 3 of 5 pages

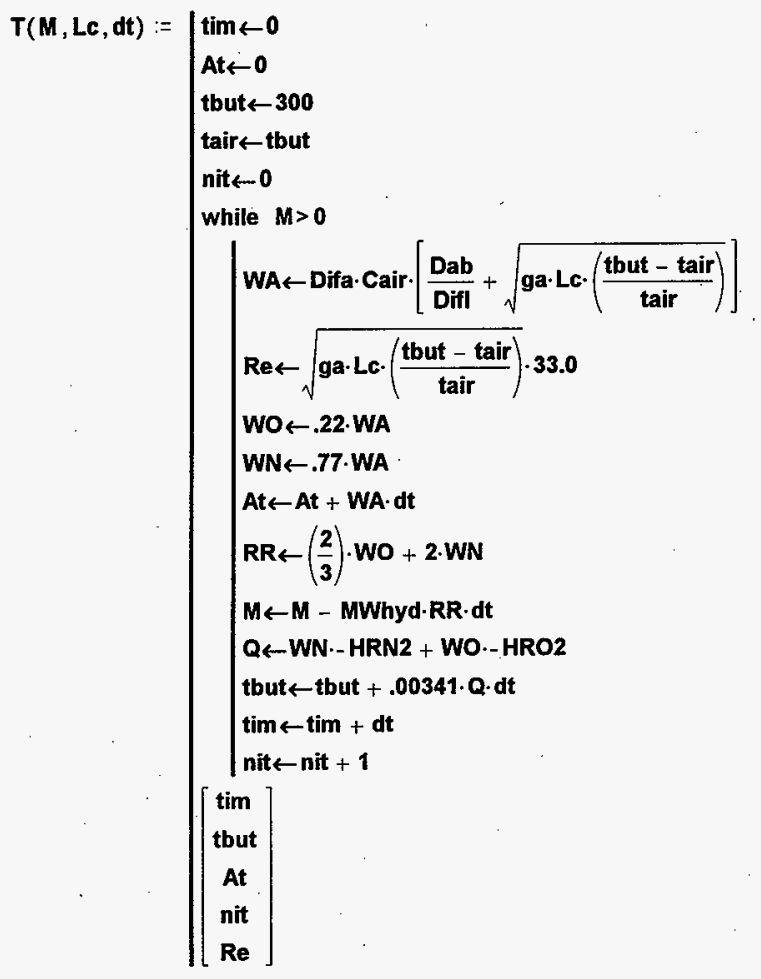

$$
T(150.0,0,400)=\left[\begin{array}{l}
5.12 \cdot 10^{4} \\
839.74273 \\
369.94501 \\
128 \\
0
\end{array}\right] T(150.0, .01,5)=\left[\begin{array}{l}
445 \\
846.53022 \\
374.59722 \\
89 \\
13.78594
\end{array}\right]
$$

AC 


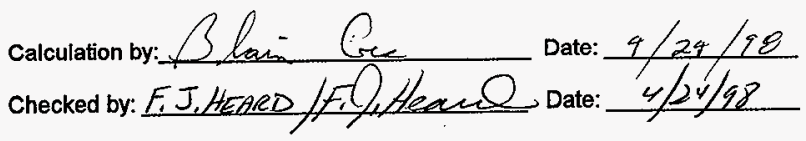

Page 4 of 5 pages

Now plot up the time to react out the hydride as a function of the mass of hydride and for several different modes. Compare the diffusion only case with the case where different characteristic lengths are used to show what the sensitivity to that parameter is.

$n:=1 . .15$

$M h_{n}:=10 \cdot n$

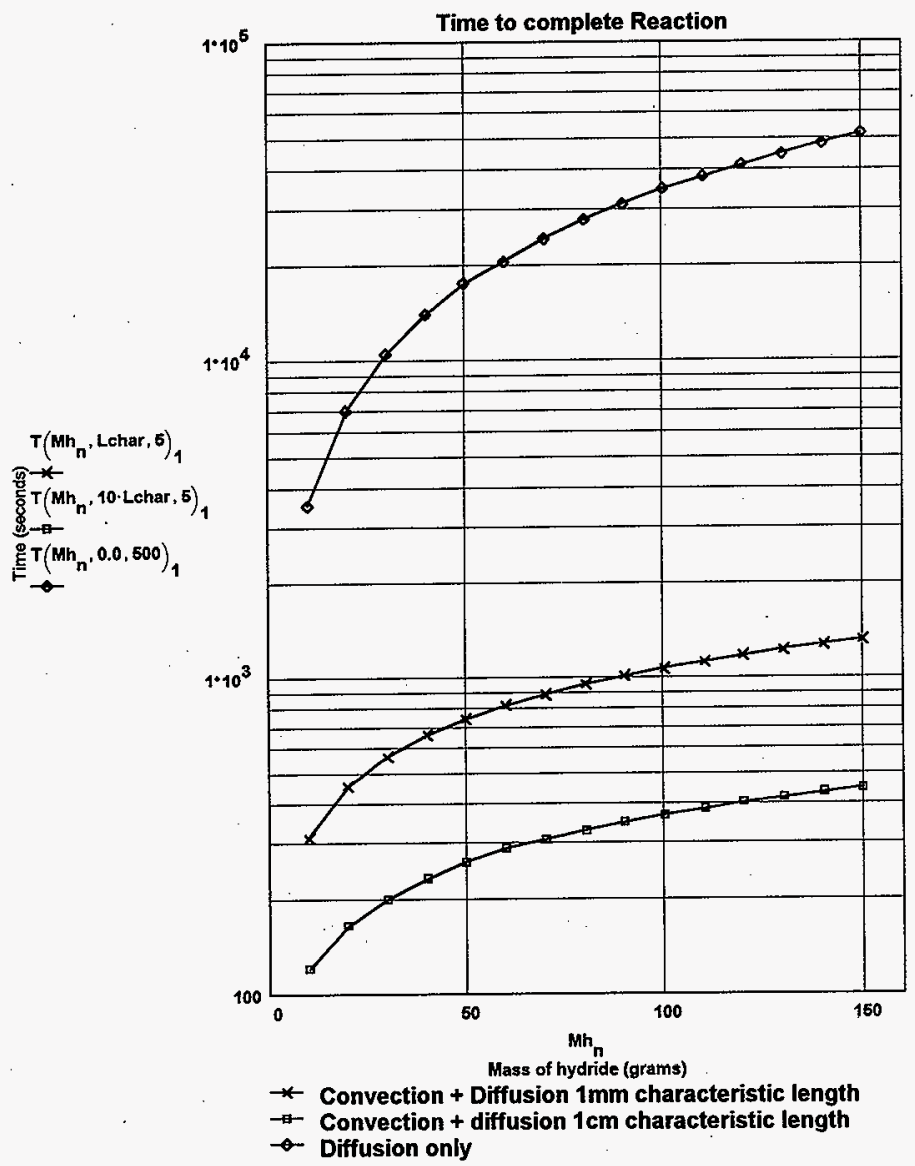


HNF-2590, Rev. 0

Calculation by: $3 / \operatorname{sen}^{5}$ (4)

Page 5 of 5 pages

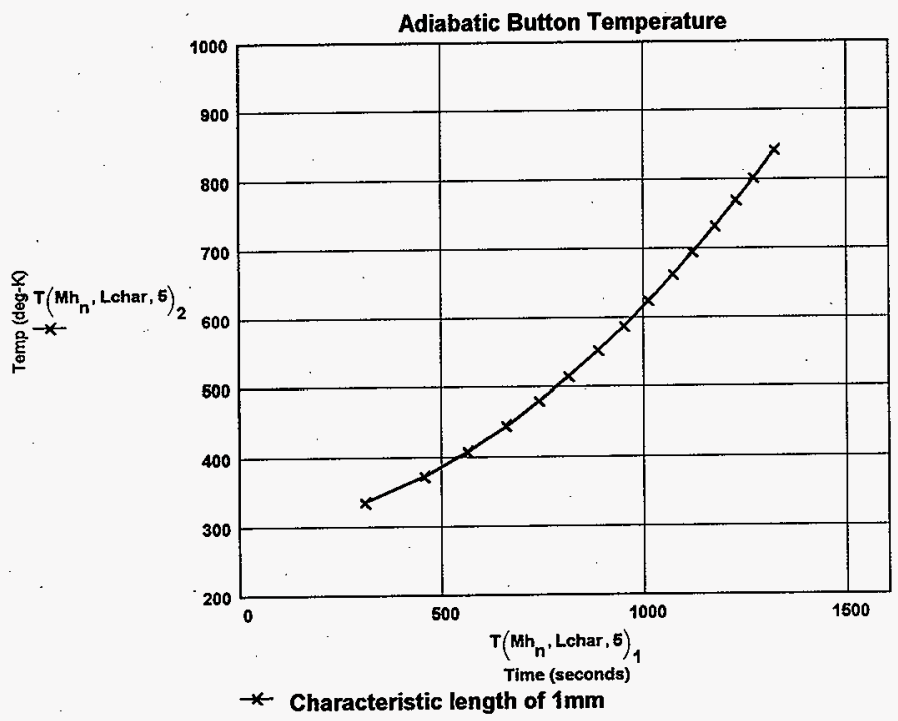


HNF-2590, Rev. 0

APPENDIX B

User FORTRAN Subroutine for Rate of Chemical Energy Production Versus Time 
subroutine heatgn (rvalue, $x, t h, z, t i m, t s n$, value, number, $n, a r g, v a l$, - ntbprs, ntab, hival, loval)

Calculate uniform volumetric heat generatin rate for Regions 35 and 36 code will mult by Region volume to obtain actual energy source split

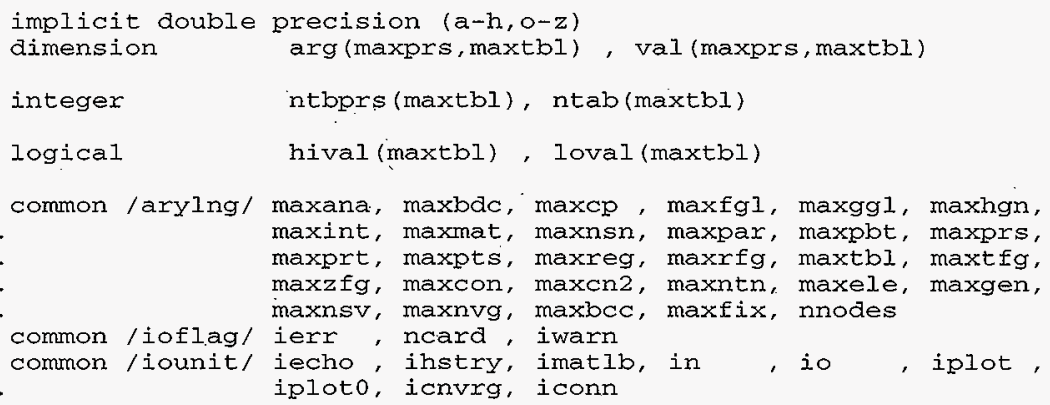


HNF-2590, Rev. 0

APPENDIX $C$

Time to Fill CHU Versus Hole Size

C-1 


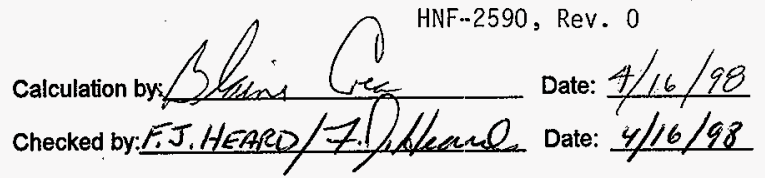

Page 1 of 3 pages

This calculation is being done to support the design of a Can Handling Unit (CHU) which will be used to expose Plutonium Hydride to air in a controlled manner. The objective is to control rate of air ingress to the can such that the reaction of this Pyrophoric material with the air won't result in a rate of energy release which will result in pressurization of the can and the subsequent expulsion and reaction of the can contents with the air in the CHU. It is postulated that the original proposal to place 3 $.25^{\prime \prime}$ holes in the lid of a can with $150 \mathrm{~g}$ of Plutonium hydride in the can will result in the can filling up with air prior to any reaction taking place, and the subsequent reaction will result in energy being generated at a rate that exceeds the capacity of the surroundings to absorb and dissipate it.

SI units will be used for this calculation with the exception that hole diameters will be shown in $\mathrm{mm}$

\section{Can Parameters}

$\begin{array}{lll}\text { Canid }:=2.607 \cdot .0254 & \mathrm{~m} & \text { Can inside diameter } \\ \text { Canht }:=2.875 \cdot .0254 & \mathrm{~m} & \text { Overall can height } \\ \text { Canwal }:=.009 \cdot .0254 & \mathrm{~m} & \text { Can wall thickness } \\ \text { Canlip }:=.11 \cdot .0254 & \mathrm{~m} & \text { Height of the lip around the can rim }\end{array}$

Calculate some of the other parameters of the problem

$$
\begin{aligned}
& \text { Cania : }=\frac{\pi}{4} \cdot \text { Canid }^{2} \quad \mathrm{~m}^{2} \quad \text { Area of the inside of the can lid } \\
& \text { Caniht := Canht }-2 \cdot(\text { Canlip + Canwal }) \quad m \quad \text { Can height between ends } \\
& \text { Canvol := Cania.Caniht } \mathrm{m}^{3} \quad \text { Volume of the can } \quad \text { Canvol }=\mathbf{0 . 0 0 0 2 3} \\
& \text { pair := .0735-16.01 Kg/M3 Standard density of air in SI units pair }=1.17674
\end{aligned}
$$

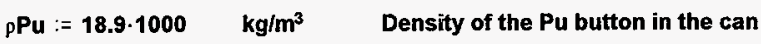

$$
\begin{aligned}
& \text { Butmas := } 2.2 \quad \mathrm{~kg} \text { Maximum mass of the Plutonium Hydride Button in can }
\end{aligned}
$$

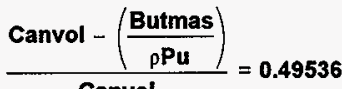

in computing the time required to fill the can the assumption is made that the velocity into the can is sonic until the can pressure is such that the pressure ratio is .53 at which point the flow reverts to simple Bernoulli flow and the velocity tapers off as the driving pressure is reduced. 


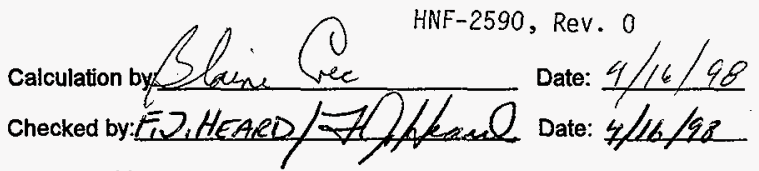

Page 2 of 3 pages

PR $:=.53$ Pressure ratio at which the flow transitions from sonic to subsonic

Define atmospheric pressure temperature and the ideal gas constant for air

$$
\begin{aligned}
& \text { Patm }:=14.7 .6894 \quad \text { Pascal's } \quad \text { Tair }:=300 \quad \text { oK } \\
& \text { Rair : }=\frac{53.34 \cdot 4.448 \cdot .3048}{.4535} \cdot 1.8 \quad \text { Newton-M/Kg-oK } \quad \text { Rair }=287.03045
\end{aligned}
$$

Define a program to return the Time required fill the can up to $95 \%$ of atmospheric pressure as a function of hole diameter based on the premise that the first $53 \%$ of the air ingress is at sonic velocities and then the balance occurs by simple Bernoulli's equation pressure loss. The calculation will be done on an isothermal basis, since the whole objective is to slow the ingress of air down to the point that significant reaction can take place in the can before all the air has been sucked in.

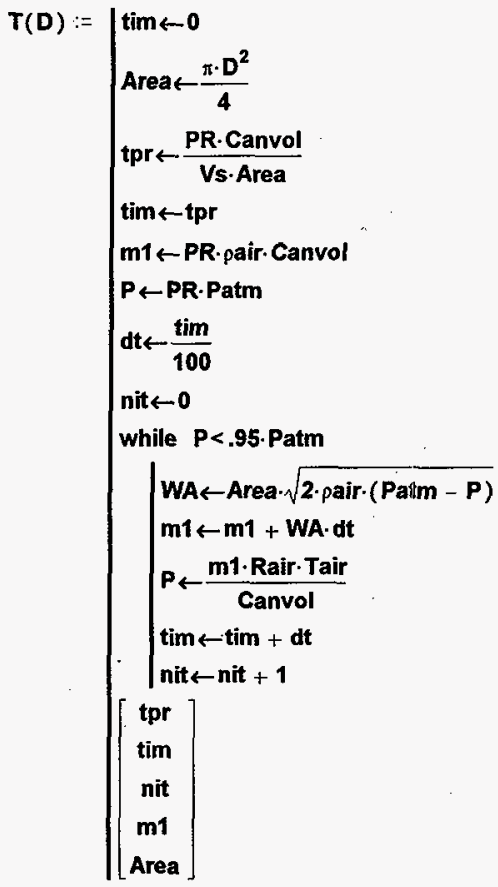




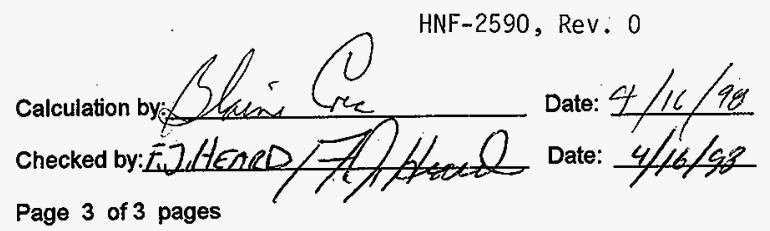

Define a range of hole sizes that may be practical to achieve. They will range from $.25 \mathrm{~mm}$ which is about 10 mils up to $5 \mathrm{~mm}$ which is slightly less than $1 / 4$ inch

$$
n:=1 . .20 \quad \text { Dia }_{n}:=\frac{n}{4000}
$$

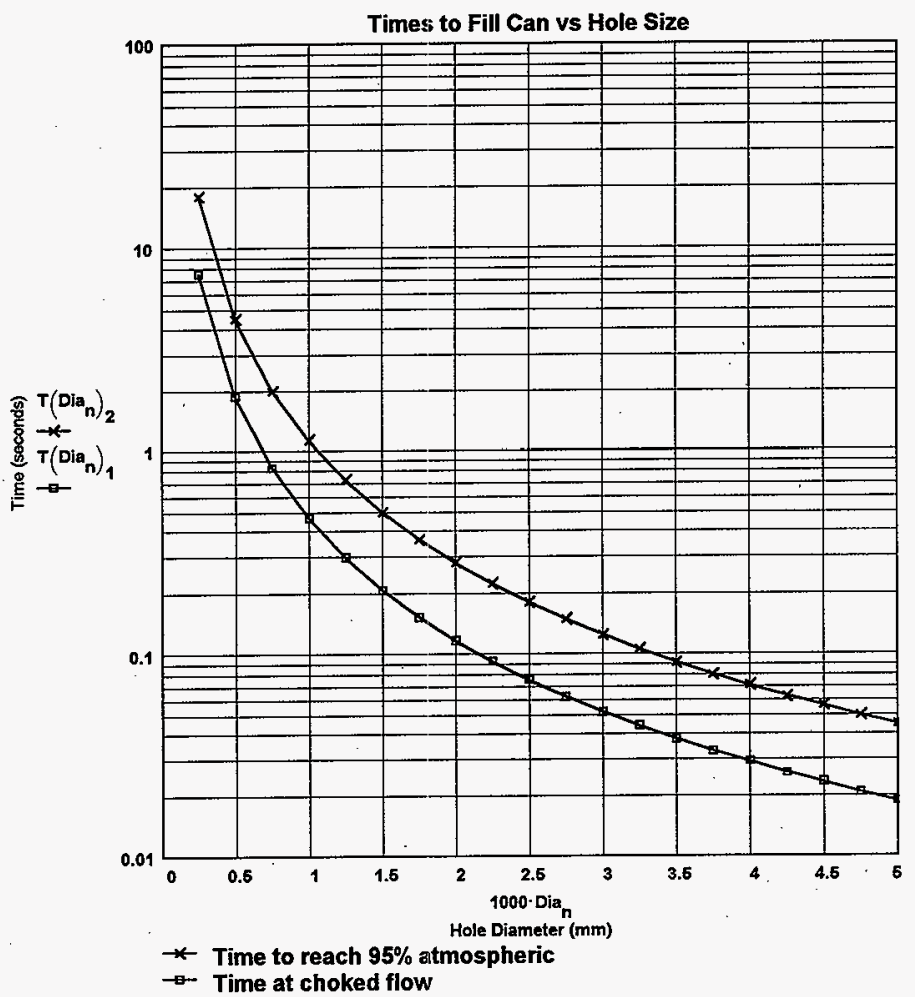




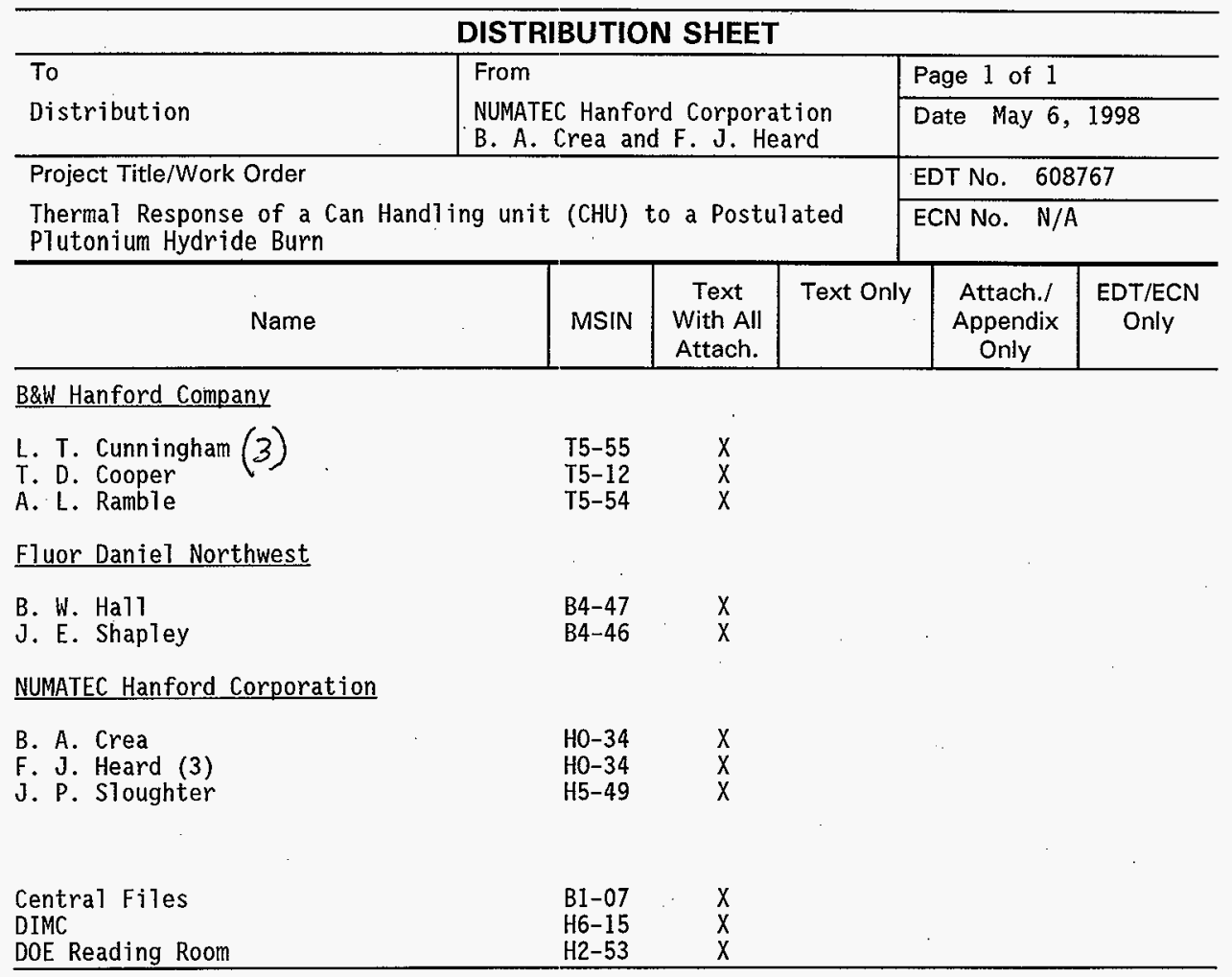

